\title{
Integrated Versus Non-Integrated Perspectives of Auditors Concerning the New ISO 9001 Revision
}

\author{
J. P. T. Domingues ${ }^{1,2}$, L. Fonseca ${ }^{1}$, P. Sampaio ${ }^{2}$ and P. M. Arezes ${ }^{2}$ \\ ${ }^{1}$ Department of Mechanical Engineering, ISEP- Polytechnic Institute of Porto, Porto, Portugal \\ ${ }^{2}$ Algoritmi Research Center, University of Minho, Braga/Guimarães, Portugal \\ (pdomingues@dps.uminho.pt)
}

\begin{abstract}
The process of integration of management systems is being unfolded by a great deal of companies nowadays. A crucial feature of it relates with the audit function and the integrated perceptions of the auditors. This issue is of utmost importance if one takes into account the remarkable effort developed by ISO in the last revisions (2015) of the ISO 9001 and ISO 14001 standards aiming at the standards integration by adopting a common high level structure, identical core context, and common terms and common definitions. The available drafts of the new ISO 45001 standard suggest the same effort. This paper aims, within a global research study on ISO 9001:2015, to report the integrated versus non-integrated perspectives of auditors concerning the new ISO 9001 revision based on the results from a survey conducted among IRCA auditors. It is intended specifically to assess if the perceptions from the auditors holding several certifications are different of those from the auditors that hold solely the QMS certification. Results suggest that the auditors holding several certifications foreseen more benefits from this new revision, i.e., auditors with a wider integrated perspective rate systematically higher the different dimensions assessed in this survey.
\end{abstract}

Keywords - Auditors, IRCA auditors, survey, integrated assessment

\section{INTRODUCTION}

The integration of Management Systems (MSs) is a current, appealing and active academic research topic addressed by a great deal of scholars all over the world. At industrial level, the integration of MSs is being developed by an increasing number of companies in order to improve and optimize their organizational issues $[1,2]$. The proper comprehension of this phenomenon requires the assessment of different perspectives namely those of the companies that implement an Integrated Management System (IMS), those of the entities that issue the standards, those of the entities that certify them and those of the experts that assess the corresponding implementation, i.e., the auditors. Several streams of bibliography are available adopting either merely descriptive or purely deductive approaches. However, the majority of the bibliography addressing the IMSs encompasses both of these approaches and a large stream of the available literature concerning this topic relies on quantitative methodologies, such as surveys, to identify and describe some of the aspects that impact on the phenomenon.
Some recent published studies addressing the integration of MSs focused on a diagnostic method to assess the IMSs after implementation [3], on the description of a potential path to achieve MSs integration [4], on the proposal of a model to assess IMSs maturity [2] and on the implementation and auditing of IMSs by companies involved in international trade [5]. In addition, other authors described how a successful MSs integration may facilitate the sustained success and development of companies [6], proposed a framework to assist companies on the implementation of an IMS [7], dissected the effect of joint MSs practices on safety and operational outcomes [8], pointed out several IMSs characteristics that match those of complex adaptive systems [9] and addressed the audit function in this new context with multiple MSs [10]. It should also be pointed out the earlier works that focused on the integration levels achieved by companies [11], on the relationships between MSs integration and macroergonomics [12], on the change of role (function to decision) of MSs [13] and the role of specific processes in the integration of MSs [14]. The new revisions of both ISO 9001 and ISO 14001 standards are also being addressed by scholars lately. Fonseca, for example, dissected both the different paths adopted from TQM to the ISO 9001:2015 and the relationship(s) between the construct of sustainability and the new ISO 14001:2015 $[15,16]$. Ultimately, the main goal of this study is to report the integrated versus non-integrated perspectives of auditors concerning the new ISO 9001 revision.

\section{METHODOLOGY}

A survey (Table A.1) was held among QMS ISO 9001 certified IRCA (International Register of Certificated Auditors) auditors in order to ascertain their perceptions and experience regarding the new revision (2015) of the ISO 9001 standard. The contacts (E-mail) of the auditors were retrieved from the IRCA website (www.irca.org). A total of 5459 auditors from 118 countries/economies were contacted in April 2016 through e-mail. The survey encompassed three groups of questions. Group 1 questions intended to ascertain the auditor features, the Group 2 questions focused on the auditor perceptions regarding the changes introduced in the new standard revision, and group 3 questions aimed at the assessment of the auditor experience at the companies where the implementation of the ISO 9001:2015 standard is being carried out. An agreement five-point scale (Do 
not agree at all (1), ..., Totally agree (5)) was adopted to assess the structured type questions (Fig. 1).

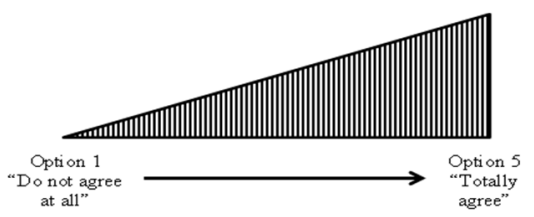

Fig. 1. Five-point agreement scale adopted.

The majority of the auditors from the population develop their activities mainly in East Asia and Pacific (36\%) and Europe (28\%)- Fig. 2. The remaining auditors account for nearly $35 \%$ of the population.

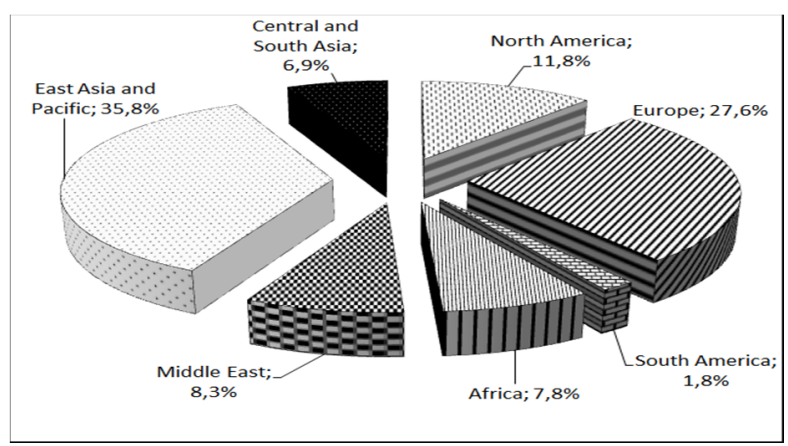

Fig. 2. Percentage of auditors- breakdown by macroregion (population).

Auditors from UK (8,7\%), Japan $(8,3 \%)$ and USA $(8 \%)$, altogether, account for nearly a fourth of the population (Fig. 3).

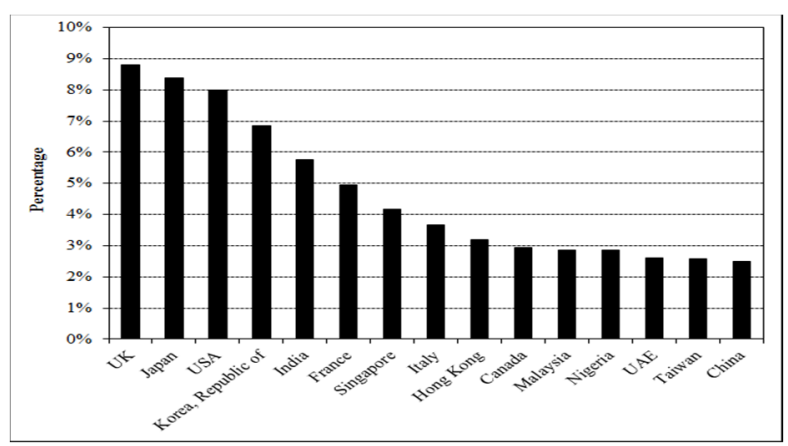

Fig. 3. Breakdown of auditors by country- Top 15 (population).

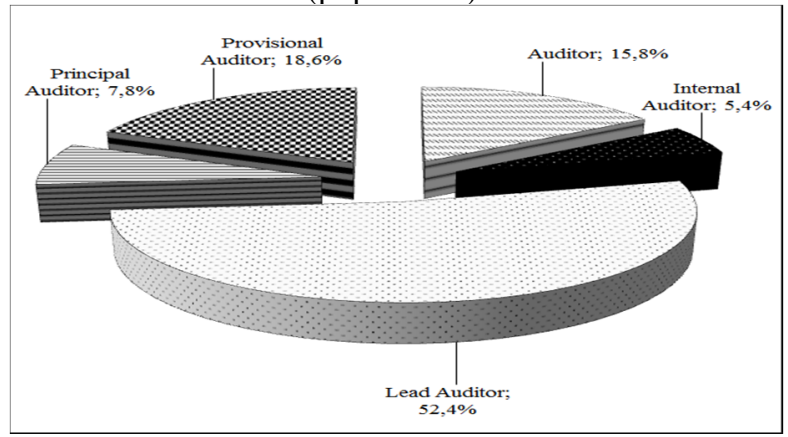

Fig. 4. Percentage of auditors- breakdown by grade (population).
Concerning their IRCA grade (Fig. 4), mainly lead auditors encompass the pool available at the IRCA website. The remaining grades account for approximately $48 \%$ of the population.

\section{RESULTS AND DISCUSSION}

\section{A. Overall Results}

A total of 393 auditors (which accounts for nearly $7,2 \%$ of the population) encompassing 71 countries answered to the survey. The analysis of the results collected through the survey, namely those aimed at the characterization of the sample, suggests that properly represents the population, i.e., conclusions may be extended to all the population. Mainly lead auditors (61\%) and auditors from Europe and East Asia and Pacific completed the survey (Fig. 5 and 6).

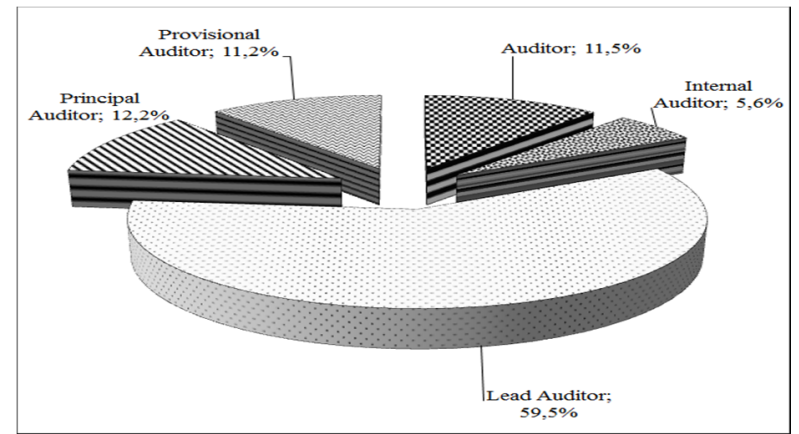

Fig. 5. Percentage of auditors- breakdown by grade (Totality of respondents).

The auditors from the remaining macro-regions accounted for nearly $45 \%$ of the total completed answers.

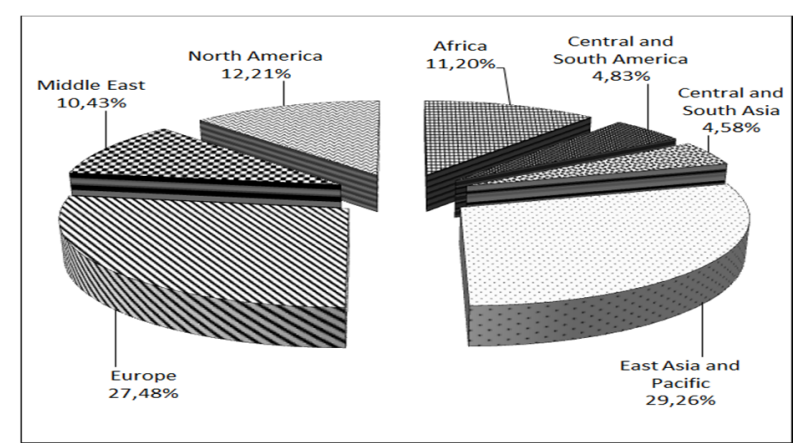

Fig. 6. Percentage of auditors- breakdown by macroregion (Totality of respondents).

At country level, auditors from United States of America (USA), United Kingdom (UK) and France (Fig. 7) contributed the most to the results attained. Considering the total number of auditors in the population, the number of respondents from Japan was lower than the potential score expected. 


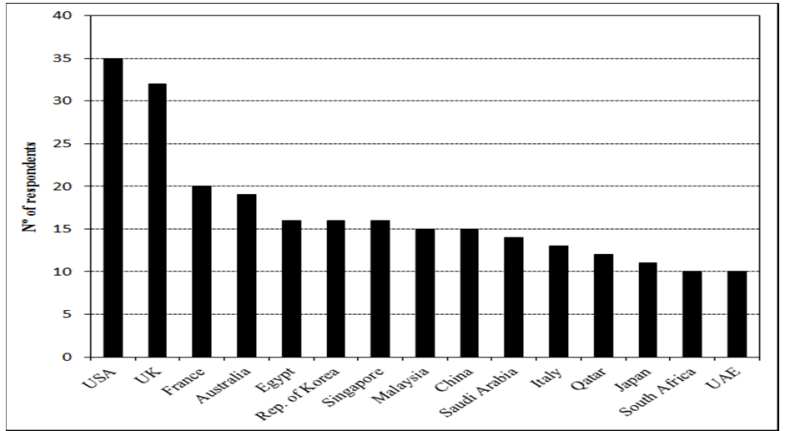

Fig. 7. Countries Top 15 (Totality of respondents).

\section{B. General perceptions from auditors}

Fig. 8 presents some of the average results collected from both the auditors that do not hold other IRCA scheme than the QMS scheme and those average results collected from the auditors that do hold other IRCA scheme in addition to the QMS scheme. Based on Fig. 8 one may stress that, with few exceptions, auditors that hold several IRCA schemes systematically rate higher all the dimensions assessed by the survey (according to the Table A.1). Concerning their perceptions regarding the new revision of the ISO 9001 standard, both groups of auditors rate lower P5 (not shown), i.e., auditors find the new revision not so easier to audit as the previous versions. On the other side, both groups of auditors find ISO 9001:2015 a useful and effective tool that companies may adopt to integrate their MSs, namely, Quality, Environment and Health and Safety MSs (P4).

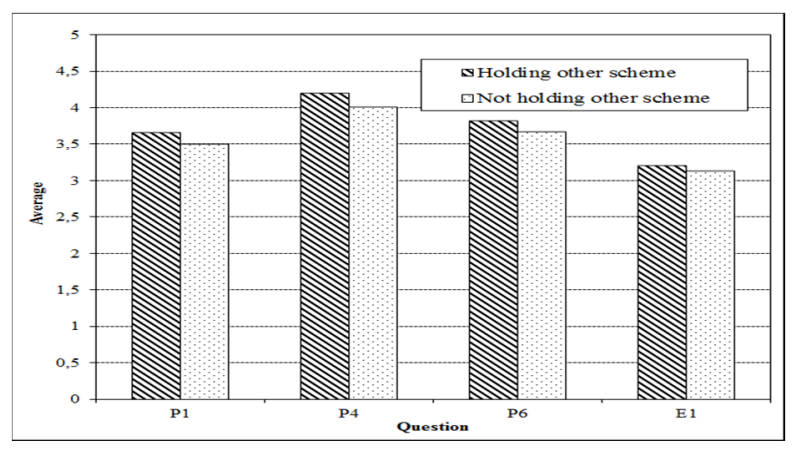

Fig. 8. Average results- Perceptions and experience auditing ISO 9001:2015 standard.

Concerning the assessed perceptions, the group of auditors that hold other IRCA scheme rate higher when compared with the group of auditors that solely hold the QMS scheme. However, both groups of auditors clearly feel that ISO 9001:2015 will be an add value to the organizations (P6). Regarding the dimensions assessed based on their experience auditing the ISO 9001:2015 one may state, based on Fig. 8, that the differences between the two groups of auditors are not so sharpen when compared with the results achieved with the perceptions regarding ISO 9001:2015 standard.

The E2 and E6 (not shown in Fig. 8) dimensions are rated higher by the group of auditors not holding other IRCA schemes, i.e., this group of auditors find the
"Change management" and "Reinforced emphasis on process approach and intended results" dimensions better implemented by the auditees companies. Auditors rate higher E8, i.e., based on their ISO 9001:2015 audit experience, auditors feel that "Improvement" has been successfully implemented by the auditees companies

\section{Analysis by Macro-Regions}

The macro-regions targeted by the analysis were the ones usually adopted in the ISO Survey of Certifications (ISO, 2015), i.e., North America, Central and South America (not shown), Europe, Africa, Middle East, East Asia and Pacific and Central and South Asia (not shown). The overall analysis of Fig. 9 to 13 suggest that both groups of auditors rate higher the perceptions regarding the new ISO 9001 standard than the field experience when auditing it. Based on Fig- 9 it is possible to point out that auditors (either holding or not holding other IRCA schemes) from North America systematically rate lower all the dimensions assessed in the survey when compared with other macro regions.

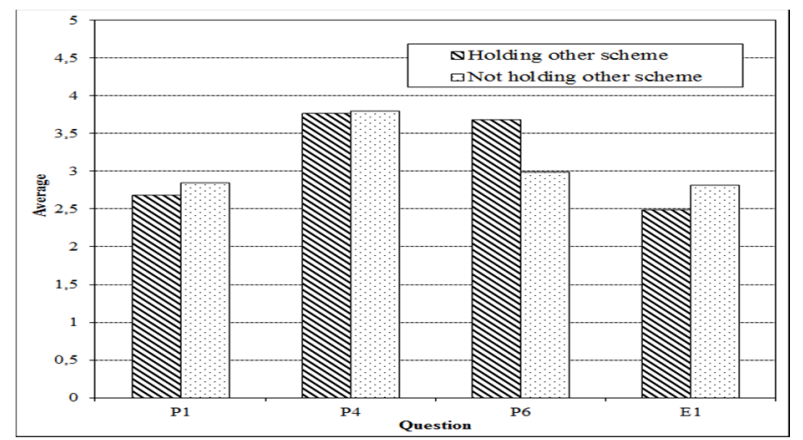

Fig. 9. Average results- North America.

Additionally, in all the macro-regions studied one can conclude that auditors find this new version of the standard as an add value to the companies that implement them. Similarly, in all the regions auditors rate lower the easiness on audit it.

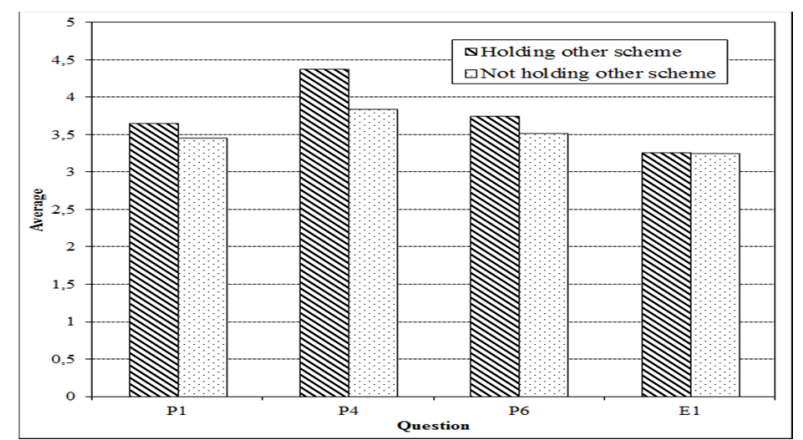

Fig. 10. Average results- Europe.

The analysis of the results from East Asia and Pacific (Fig. 12) shows that auditors with a wider integrated perspective (holding more than the IRCA QMS scheme) consistently rate higher the dimensions assessed. This concurs with the results presented in the previous section, 
i.e., auditors with a more in depth integrated perspective seem to perceive more benefits from the ISO 9001:2015 when compared with other versions.

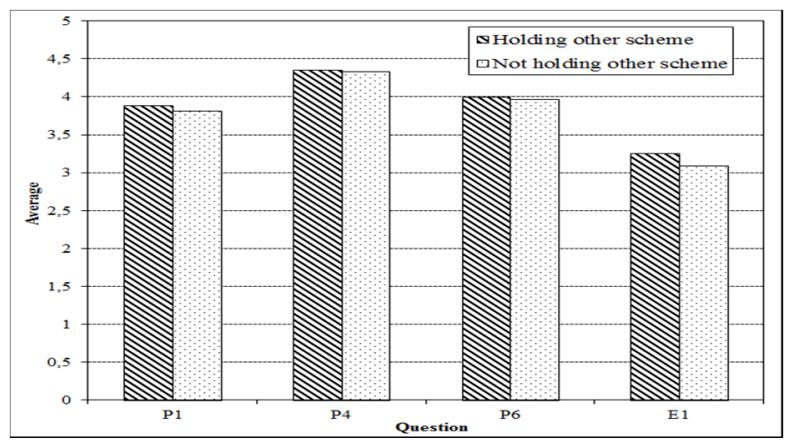

Fig. 11. Average results- Africa.

It should be pointed out that all regions rate higher $\mathrm{P} 4$, i.e., auditors feel that this new version of the standard promotes the integration of MSs and one should stress that, with exception of Central and South America, the auditors holding other IRCA schemes rate higher P4 than the ones not holding other IRCA schemes.

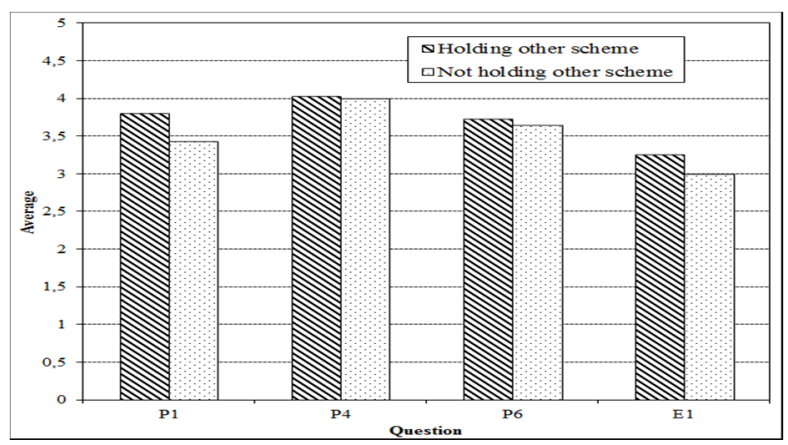

Fig. 12. Average results- East Asia and Pacific.

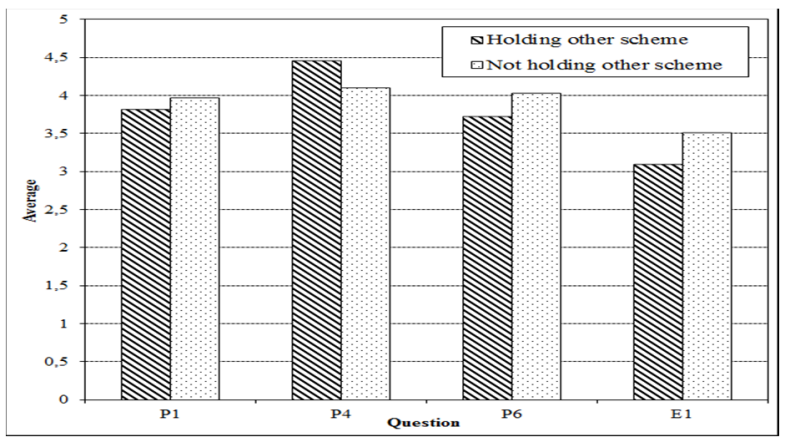

Fig. 13. Average results- Middle East.

\section{Analysis by IRCA grade}

The analysis of the results according to the IRCA QMS grade of the auditors is presented in Fig. 14. Auditors and lead auditors display a similar behavior concerning their perceptions (P1, P4 and P6) and experience (E1). Both auditors and lead auditors holding several IRCA schemes rate higher the dimensions evaluated. The majority of the respondents strongly feel that the new ISO 9001 version will properly assist in the integration of MSs (P4). On the other side, the majority of the respondents rate lower E1, i.e., they feel that, at this stage, "High level structure, identical core context, and common terms and common definitions" are not completely and successfully implemented in the auditees companies.

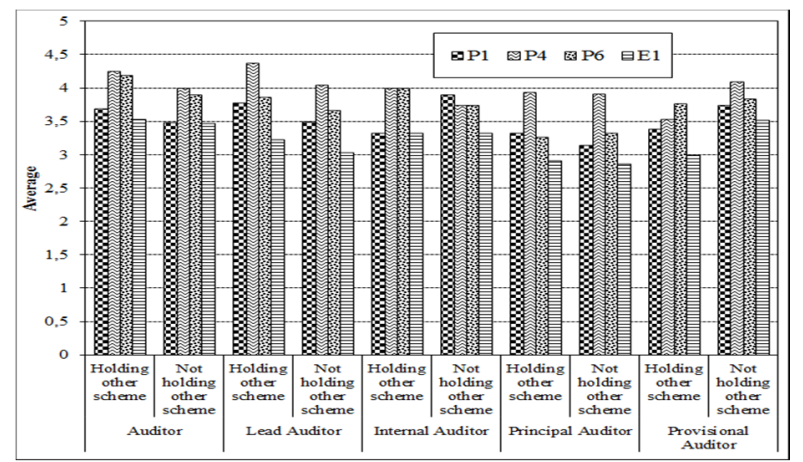

Fig. 14. Average results breakdown by IRCA grade.

\section{CONCLUSION}

Although the need of a further in depth analysis, globally, results suggest that the assessment from auditors holding several IRCA schemes is different from those solely holding the QMS scheme regarding their perceptions and experience with the ISO 9001 standard. This different behavior is more pronounced if one considers the results from auditors and lead auditors. Additionally, auditors with a wider integrated perspective rate systematically higher the dimensions assessed by the survey. A dimension rated lower by both groups of auditors concerns with the easiness in auditing the standard. Furthermore, results suggest that auditors, at this stage, do not feel completely comfortable regarding the audit process. In our view, the results from this survey, although focused specifically on the ISO 9001:2015 standard, have the potential to be transferable to the new ISO 14001:2015 and ISO 45001 (not yet published). All the dimensions assessed in this survey have similar dimensions in these standards. In order to overcome some limitations of the current paper it is intended, in the near future (one year), to conduct the same survey in order to assess the evolution of both the perceptions and the experience of the auditors throughout the transition phase. In addition, a deeper statistical analysis (work in progress) will provide a clearer, thorough and meaningful understanding of the results collected.

\section{ACKNOWLEDGMENT}

The authors would like to thank to all the responding auditors for their great collaboration and will pursue this study by applying more powerful statistical tools and adding a time perspective by replicating the survey in the future. This study had the financial support of FCTFundação para a Ciência e Tecnologia of Portugal under the project UID/CEC/00319/2013. Pedro Domingues is 
supported by FCT Post-Doc Grant Reference SFRH/BPD/103322/2014.

\section{REFERENCES}

[1] J.P.T. Domingues, P. Sampaio and P.M. Arezes, "Analysis of integrated management systems from various perspectives", Total Quality Management and Business Excellence, vol. 26, no. 11-12, pp. 1311-1334, 2015.

[2] J.P.T. Domingues, P. Sampaio and P.M. Arezes, "Integrated management systems assessment: a maturity model proposal", Journal of Cleaner Production, vol. 124, pp. 164-174, 2016.

[3] S.V. Bonato and C.S.T. Caten, "Diagnóstico da integração dos sistemas de gestão ISO 9001, ISO 14001 e OHSAS 18001", Production, vol. 25, no. 3, pp. 626-640, 2015.

[4] S. Malki, "Towards an Integrated Management System: A Hypothetical Case", Journal of Management Policy and Practice, vol. 17, no. 1, pp. 71-88, 2016.

[5] A.G. Raišienè and I. Arbidane, "International trade and implementation and auditing of IMS: The managerial viewpoint", International Economics Letters, vol. 4, no. 2, pp. 66-79, 2015.

[6] M.F. Rebelo, G. Santos and R. Silva, "Integration of management systems: Towards a sustained success and development of organizations", Journal of Cleaner Production, in press, doi: 10.1016/j.jclepro.2016.04.011, 2016.

[7] G.M. Rosa and J.C. Toledo, "Proposal for a framework to support the integration process of standardized management systems", in Proc. of the XXII Simpósio de Engenharia de Produção, Bauru- São Paulo, Brazil, pp.2-15, 2015.

[8] E. Tompa, L. Robson, A. Sarnocinska-Hart, R. Klassen, A. Shevchenko, S. Sharma, S. Hogg-Johnson, B.C. Amick, D.A. Johnston, A. Veltri and M. Pagell, "Managing safety and operations: The effect of joint management system practices on safety and operational outcomes", Journal of Occupational and Environmental Medicine, vol. 58, no. 3, pp. 80-89, 2016.

[9] J.P.T. Domingues, P. Sampaio and P.M. Arezes, "Integrated management systems as complex adaptive systems" in Proc. of the $8^{\text {th }}$ WOS.net International, WOS.net 2016, Porto, Portugal, pp. -, 2016.

$[10]$ W. Cook, S. van Bommel and E. Turnhout, "Inside environmental auditing: effectiveness, objectivity, and transparency", Current Opinion in Environmental Sustainability, vol. 18, pp. 33-39, 2016.

[11] P. Sampaio, P. Saraiva and J.P.T. Domingues, "Management systems: Integration or addition?", International Journal of Quality and Reliability Management, vol. 29, no. 4, pp. 402-424, 2012.

[12] J.P.T. Domingues, P. Sampaio and P.M. Arezes, "New organizational issues and macroergonomics: Integrating management systems", International Journal of Human Factors and Ergonomics, vol. 1, no. 4, pp. 351-375, 2012.

[13] V. Leopoulos, D. Voulgaridou, E. Bellos and K. Kirytopoulos, "Integrated management systems: moving from function to organisation/decision view", The TQM Journal, vol. 22, no. 6, pp. 594-628, 2010.

[14] N. Zivkovic, I. Mijatovic, I. Janicijevic and M. Kudumovic, "The role of design and development process in integration of management systems", Technics Technologies Education Management, vol. January, pp. 88-99, 2010.

[15] Fonseca, L., "From Quality gurus and TQM to ISO 9001:2015: a review of several quality paths", International
Journal for Quality Research, vol. 9, no. 1, pp.167-180, $2015 \mathrm{a}$.

[16] Fonseca, L., "ISO 14001:2015: An Improved Tool for Sustainability", Journal of Industrial Engineering and Management, vol. 8, no. 1, pp.37-50, 2015 b.

\section{APPENDIX}

TABLE A1.

SURVEY CORE STRUCTURE.

\begin{tabular}{|c|c|}
\hline Description & \\
\hline \multirow{9}{*}{$\begin{array}{l}\text { Auditor } \\
\text { Features }\end{array}$} & $\begin{array}{l}\text { How many years of experience do you have on } \\
\text { Auditing? }\end{array}$ \\
\hline & $\begin{array}{l}\text { How many ISO } 9001: 2015 \text { audits have you performed } \\
\text { so far? }\end{array}$ \\
\hline & $\begin{array}{l}\text { For how many years do you hold IRCA QMS (ISO } \\
\text { 9001) auditor certification? }\end{array}$ \\
\hline & Which IRCA QMS grade do you hold? \\
\hline & Do you hold other IRCA auditor certification? \\
\hline & What is your primary geographical area of audit work? \\
\hline & In which country do you primarily conduct audits? \\
\hline & What is your primary audit sector of activity? \\
\hline & What is your primary audit sector of activity? \\
\hline \multirow{6}{*}{$\begin{array}{c}\text { Auditor } \\
\text { Perceptions }\end{array}$} & $\begin{array}{l}\text { P1: Concerning the overall clarity of requirements, do } \\
\text { you agree that ISO } 9001: 2015 \text { is more clear than } \\
\text { previous ISO } 9001 \text { versions? }\end{array}$ \\
\hline & $\begin{array}{l}\text { P2: Do you agree that ISO } 9001: 2015 \text { is in line with } \\
\text { modern business management concepts? }\end{array}$ \\
\hline & $\begin{array}{l}\text { P3: Do you agree that ISO } 9001: 2015 \text { is in line with } \\
\text { modern quality management concepts? }\end{array}$ \\
\hline & $\begin{array}{l}\text { P4: Do you agree that ISO 9001:2015 is more effective } \\
\text { for organization Management Systems integration }\end{array}$ \\
\hline & $\begin{array}{l}\text { P5: Do you agree that ISO } 9001: 2015 \text { will be easier to } \\
\text { audit than previous ISO } 9001 \text { versions? }\end{array}$ \\
\hline & $\begin{array}{l}\text { P6: Taking an overall perspective, do you agree that } \\
\text { ISO 9001:2015 will be most valuable to ISO } 9001 \\
\text { certified organizations? }\end{array}$ \\
\hline \multirow{8}{*}{$\begin{array}{c}\text { Auditor } \\
\text { Experience }\end{array}$} & $\begin{array}{l}\text { E1: Based on your ISO 9001:2015 audit experience, do } \\
\text { you agree that "High level structure, identical core } \\
\text { context, and common terms and common definitions" } \\
\text { has been successfully implemented by the auditee } \\
\text { organizations? }\end{array}$ \\
\hline & $\begin{array}{l}\text { E2: Based on your ISO 9001:2015 audit experience, do } \\
\text { you agree that "Change management" has been } \\
\text { successfully implemented by the auditee organizations? }\end{array}$ \\
\hline & $\begin{array}{l}\text { E3: Based on your ISO } 9001: 2015 \text { audit experience, do } \\
\text { you agree that "Understanding the organization and its } \\
\text { context" has been successfully implemented by the } \\
\text { auditee organizations? }\end{array}$ \\
\hline & $\begin{array}{l}\text { E4: Based on your ISO } 9001: 2015 \text { audit experience, do } \\
\text { you agree that "Understanding the needs and } \\
\text { expectations of interested parties" has been } \\
\text { successfully implemented by the auditee organizations? }\end{array}$ \\
\hline & $\begin{array}{l}\text { E5: Based on your ISO } 9001: 2015 \text { audit experience, do } \\
\text { you agree that "Adoption of Risk-based thinking" has } \\
\text { been successfully implemented by the auditee } \\
\text { organizations? }\end{array}$ \\
\hline & $\begin{array}{l}\text { E6: Based on your ISO } 9001: 2015 \text { audit experience, do } \\
\text { you agree that "Reinforced emphasis on process } \\
\text { approach and intended results" has been successfully } \\
\text { implemented by the auditee organizations? }\end{array}$ \\
\hline & $\begin{array}{l}\text { E7: Based on your ISO } 9001: 2015 \text { audit experience, do } \\
\text { you agree that "Less emphasis on prescriptive } \\
\text { requirements and on documentation" has been } \\
\text { successfully implemented by the auditee organizations? }\end{array}$ \\
\hline & $\begin{array}{l}\text { E8: Based on your ISO } 9001: 2015 \text { audit experience, do } \\
\text { you agree that "Improvement" has been successfully } \\
\text { implemented by the auditee organizations? }\end{array}$ \\
\hline
\end{tabular}

